\title{
The immunomodulatory effect of cathelicidin-B1 on chicken macrophages
}

\author{
Lianci Peng, Maaike R. Scheenstra, Roel M. van Harten, Henk P. Haagsman and Edwin J. A. Veldhuizen* (1)
}

\begin{abstract}
Cathelicidins (CATHs) play an important role in the innate immune response against microbial infections. Among the four chicken cathelicidins, CATH-B1 is studied the least. In this study, the effect of CATH-B1 on the macrophage response towards avian pathogenic E. coli (APEC) and bacterial ligands was investigated. Our results show that APEC induced CATH-B1 gene expression in both a chicken macrophage cell line (HD11 cells) and primary macrophages, while expression of the other three CATHs was virtually unaffected. While the antimicrobial activity of CATH-B1 is very low under cell culture conditions, it enhanced bacterial phagocytosis by macrophages. Interestingly, CATH-B1 downregulated APEC-induced gene expression of pro-inflammatory cytokines (IFN- $\beta$, IL-1 $\beta$, IL-6 and IL-8) in primary macrophages. In addition, CATH-B1 pre-incubated macrophages showed a significantly higher gene expression of IL-10 after APEC challenge, indicating an overall anti-inflammatory profile for CATH-B1. Using isothermal titration calorimetry (ITC), CATH-B1 was shown to bind LPS. This suggests that CATH-B1 reduces toll like receptor (TLR) 4 dependent activation by APEC which may partly explain the decreased production of pro-inflammatory cytokines by macrophages. On the contrary, direct binding of CATH-B1 to ODN-2006 enhanced the TLR21 dependent activation of macrophages as measured by nitric oxide production. In conclusion, our results show for the first time that CATH-B1 has several immunomodulatory activities and thereby could be an important factor in the chicken immune response.
\end{abstract}

Keywords: chicken, innate immunity, macrophages, antimicrobial peptides, cathelicidins, E. coli

\section{Introduction}

Cathelicidins are host defense peptides (HDPs) with antimicrobial activity and immunomodulatory functions. They are produced as inactive precursors (prepropeptides), stored in granules, and upon cell activation released as mature peptides by proteolytic cleavage [1]. Cathelicidins have been found in many different species, including mammals, reptiles, amphibians, fishes and birds [2, 3]. Interestingly, the number of functional genes encoding cathelicidins in different species is highly variable [4]. For example, only a single cathelicidin (LL-37) is present in human, while chicken has four cathelicidins

\footnotetext{
*Correspondence: e.j.a.veldhuizen@uu.nl

Department of Biomolecular Health Sciences, Division of Infectious

Diseases \& Immunology, Section of Molecular Host Defence, Faculty of Veterinary Medicine, Utrecht University, Yalelaan 1, 3584CL Utrecht, The Netherlands
}

with varying length and structure $(\mathrm{CATH}-1,-2,-3$ and -B1) [5-8].

Of the four chicken cathelicidins, CATH-2 has been studied extensively. CATH-2 has broad antimicrobial activity and strong immunomodulatory effects, such as lipopolysaccharide (LPS) binding, neutralization of the immune response and enhanced DNA-induced activation of toll like receptor (TLR) 21 [9-12]. In addition, in ovo administration of the all D-amino acid enantiomer of CATH-2 (D-CATH-2) at embryonic day 18 resulted in a protective effect against avian pathogenic $E$. coli (APEC) infection up to 7 days after hatch [13]. However, less is known about the activities of CATH-B1, which means that it is challenging to properly compare functionalities and activities [14]. When comparing expression patterns, one clear difference between CATH-1, -2, -3 and CATH-B1 is apparent: using immunostaining and mass 
spectrometry CATH-1, -2, -3 were detected in heterophils [15], while CATH-B1 was shown to be produced by epithelial cells in the bursa of Fabricius, although an extended description of CATH-B1 protein expression among cells/tissues was not described [6].

APEC is an important pathogen that causes severe respiratory diseases in chicken, leading to huge economic losses in poultry farming. APEC infection starts in the trachea and damages the respiratory mucosa. Subsequently, it crosses the epithelial layer and enters the blood stream spreading to other tissues [16]. APEC can be phagocytosed by macrophages both in the lungs and in the blood stream, which leads to (partial) killing of the pathogen, but also induces an immune response that attracts other immune cells such as heterophils to infected sites.

Compared to mammalian lungs, the healthy chicken lung has a relatively low number of macrophages, but a large increase in number of macrophages occurs in the lung and air sacs after APEC infection [17-19]. This suggests that macrophages play an important role against microbial infection in the chicken lung. Interestingly, bacterial metabolites such as butyrate induced the gene expression of CATH-B1 in chicken macrophages including HD11 cells and primary monocytes, whereas gene expression of the other three cathelicidins was very low in macrophages compared to heterophils [20]. This is an indication that CATH-B1 might play an important role in macrophages upon interaction with $E$. coli.

Therefore, in this study, our main aim was to investigate the effect of CATH-B1 on chicken macrophages and their response towards APEC and TLR agonists. We found that gene expression of CATH-B1 was induced by APEC in both HD11 cells and blood monocyte-derived macrophages. CATH-B1 enhanced phagocytosis of APEC by macrophages. Furthermore, CATH-B1 inhibited APECand LPS- induced immune response but enhanced DNAinduced nitric oxide (NO) in macrophages. Our study provides additional insights in the functions of CATH$\mathrm{B} 1$, that are clearly different from those of the other chicken cathelicidins.

\section{Methods and materials \\ Peptides}

All peptides were synthesized by China Peptides (Shanghai, China) using Fmoc-chemistry and purified by reverse phase high-performance liquid chromatography to a purity of $>95 \%$.

\section{Bacterial strains}

The APEC strain is a clinical isolate from chicken [13]. Heat-killed bacteria were prepared by heating the bacterial suspension at $75{ }^{\circ} \mathrm{C}$ for $15 \mathrm{~min}$. Viability was checked by plating out on Tryptic Soy Agar (TSA) (Oxoid, Basingstoke, UK) plates.

\section{Antimicrobial activity assay}

APEC was cultured in Tryptic Soy Broth (TSB) (Oxoid, Basingstoke, UK) at $37{ }^{\circ} \mathrm{C}$ and grown to mid-logarithmic growth phase before testing. Bacterial suspensions were pelleted by centrifugation, resuspended in TSB or Gibco cell culture medium (RPMI1640 or DMEM + glutamax (Thermo Fischer Scientific, Waltham, MA, USA)) with 10\% FCS (Corning, Glendale, USA) and diluted to $2.0 \times 10^{6} \mathrm{CFU} / \mathrm{mL}$. Twenty-five $\mu \mathrm{L}$ of cathelicidins $(0-80 \mu \mathrm{M})$ were mixed with an equal volume of bacterial suspension and incubated for $3 \mathrm{~h}$ at $37{ }^{\circ} \mathrm{C}$. After incubation, dilution series of bacteria were plated out on TSA plates and incubated at $37{ }^{\circ} \mathrm{C}$ for $24 \mathrm{~h}$ to quantify viable bacteria.

\section{Cell culture}

Monocyte-derived macrophages were obtained as described before [21]. In short, peripheral blood mononuclear cells (PBMCs) were isolated from blood of 76-week-old healthy chickens using Ficoll density gradient centrifugation and were frozen in liquid nitrogen until use. PBMCs $\left(1 \times 10^{7}\right.$ cells) were seeded in a 24 -well plate and incubated at $41{ }^{\circ} \mathrm{C}\left(5 \% \mathrm{CO}_{2}\right)$. After overnight culture, all non-attached cells were removed and attached cells (monocytes) were maintained in RPMI1640 + glutamax medium with $10 \%$ FCS and 1\% P/S (100 U penicillin/ $\mathrm{mL} ; 100 \mu \mathrm{g}$ streptomycin/mL (Thermo Fischer Scientific, Waltham, MA, USA) supplemented with recombinant chicken GM-CSF produced in COS-7 cells for another 2 days at $41{ }^{\circ} \mathrm{C}\left(5 \% \mathrm{CO}_{2}\right)$ [22]. These monocyte-derived macrophages were used for further analysis.

The chicken macrophage cell line HD11 was maintained in RPMI1640-glutamax supplemented with $10 \%$ FCS and $1 \% \mathrm{P} / \mathrm{S}$ at $41{ }^{\circ} \mathrm{C}\left(5 \% \mathrm{CO}_{2}\right)$. HD11 cells were seeded in a 24 -well plate $\left(2.5 \times 10^{5}\right.$ cells/well $)$ or 96-well plate $\left(0.5 \times 10^{5}\right.$ cells/well $)$ and cultured overnight to adhere before further analysis.

Mouse macrophages (RAW 264.7 cells) were maintained in DMEM-glutamax supplemented with $10 \%$ FCS at $37{ }^{\circ} \mathrm{C}\left(5 \% \mathrm{CO}_{2}\right)$. RAW cells were seeded in a 96-well plate $\left(0.5 \times 10^{5}\right.$ cells/well $)$ and cultured overnight to adhere before further analysis.

\section{Cell viability}

Cell viability was determined using the WST-1 assay following the manufacturer's protocol. Briefly, primary macrophages were incubated with cathelicidins for $3 \mathrm{~h}$ at $41{ }^{\circ} \mathrm{C}\left(5 \% \mathrm{CO}_{2}\right)$. Subsequently, cells were washed and further incubated for $3 \mathrm{~h}$ at $41{ }^{\circ} \mathrm{C}$. Cell culture medium was removed and replaced with fresh culture medium 
containing 10\% WST-1 reagent (Roche, Mannheim, Germany). After 20 min incubation, absorbance was measured at $450 \mathrm{~nm}$ with a FLUOstar Omega microplate reader and was corrected for absorbance at $630 \mathrm{~nm}$.

\section{APEC infection in chicken macrophages}

Primary macrophages and HD11 cells were cultured as described above. Aliquots of $0.5 \mathrm{~mL}$ of bacterial suspensions $\left(1 \times 10^{6} \mathrm{CFU} / \mathrm{mL}\right)$ were added to each well in the presence or absence of $5 \mu \mathrm{M}$ CATH-B1 or CATH-2, with three replicate wells for a 24-well plate and incubated for $3 \mathrm{~h}$ at $41{ }^{\circ} \mathrm{C}\left(5 \% \mathrm{CO}_{2}\right)$. In phagocytosis studies, bacteria were removed at $3 \mathrm{~h}$ post infection and cells were washed three times with RPMI1640-glutamax medium with $10 \%$ FCS. Then, RPMI 1640-glutamax containing $500 \mu \mathrm{g} / \mathrm{mL}$ gentamicin (Sigma-Aldrich) was added to cells in order to kill all extracellular, non-phagocytosed bacteria and plates were put back at $41{ }^{\circ} \mathrm{C}$ for $1 \mathrm{~h}$. Infected cells were washed three times with RPMI1640-glutamax and lysed by $0.5 \mathrm{~mL} 0.5 \%$ Triton X-100. After lysis, dilution series of cells were plated on TSA plates and incubated at $37{ }^{\circ} \mathrm{C}$ for $24 \mathrm{~h}$ to quantify viable bacteria.

In pre-incubation studies, CATH-B1 was added to primary macrophages for $3 \mathrm{~h}$, washed away with cell culture medium after which APEC were added for $3 \mathrm{~h}$. In postincubation studies, APEC were added to primary macrophages for $3 \mathrm{~h}$, washed away and infected cells were treated with CATH-B1 with gentamicin for $3 \mathrm{~h}$. After that, cells were treated with TRIzol (Thermo Fisher Scientific, Waltham, MA, USA) for RNA isolation.

\section{LPS and ODN-2006 stimulation}

Primary macrophages and RAW cells were cultured as described above. UltraPure LPS E. coli O111:B4 (100 ng/ $\mathrm{mL}$ ) (InvivoGen, San Diego, CA, USA), was diluted in RPMI1640-glutamax medium with 10\% FCS, and added to cells in the presence or absence of $5 \mu \mathrm{M}$ CATH-B1 or CATH-2 for $4 \mathrm{~h}$. Afterwards, primary macrophages were washed and treated with TRIzol for RNA isolation.

HD11 cells were prepared in a 96-well plate as described above. ODN-2006 (5 nM) (InvivoGen, Toulouse, France) was added to HD11 cells in the presence or absence of different concentrations $(0-10 \mu \mathrm{M})$ of CATHB1 or CATH-2 for $20 \mathrm{~h}$. After this incubation, cell supernatants were collected to measure NO production (see below).

\section{Quantitative real-time PCR (qPCR)}

Primary macrophages were treated with APEC and LPS as described above. After incubation, total RNA was extracted by TRIzol reagent according to the manufacturer's instructions. RNA (500 ng) was reverse transcribed by the iScript cDNA synthesis kit (Bio-Rad, Veenendaal, the Netherlands) according to the manufacturer's instructions. Primers and probes were designed and produced by Eurogentec (Seraing, Belgium) (Table 1). qPCR was performed in clear thin-walled 96 well plates (Biorad, Hercules, CA, USA) using adhesive seals (Biorad ' $\mathrm{B}$ ' seals) on a CFX Connect qPCR with CFX Manager 3.0 (Bio-Rad). All reactions were performed in Biorad IQ supermix (or IQ Sybrgreen supermix for CATH-2) with $300 \mathrm{nM}$ forward and reverse primer and $100 \mathrm{nM}$ probe and $25 \mathrm{ng}$ cDNA as template. Cycling conditions were similar for all PCR reactions: $3 \mathrm{~min}$ at $95^{\circ} \mathrm{C}$; 40 cycles: $10 \mathrm{~s}$ at $95^{\circ} \mathrm{C}, 30 \mathrm{~s}$ at $60^{\circ} \mathrm{C}$ and $30 \mathrm{~s}$ at $72{ }^{\circ} \mathrm{C}$, resulting in cycling efficiencies between $90 \%$ and $110 \%$. Relative gene expression levels were normalized against the expression levels of the reference genes GAPDH and 28S. Under the

\section{Table 1 Primer and probe sequences for qPCR}

\begin{tabular}{|c|c|c|}
\hline Gene & $5^{\prime} \rightarrow 3^{\prime}$ sequence & Accession number \\
\hline \multirow[t]{3}{*}{ GAPDH } & F: GTCAACCATGTAGTTCAGATCGATGA & NM_204305.1 \\
\hline & R: GCCGTCCTCTCTGGCAAAG & \\
\hline & P: AGTGGTGGCCATCAATGATCCC & \\
\hline \multirow[t]{3}{*}{$28 \mathrm{~S}$} & F: GGCGAAGCCAGAGGAAACT & X59733 \\
\hline & R: GACGACCGATTTGCACGTC & \\
\hline & P: AGGACCGCTACGGACCTCCACCA & \\
\hline \multirow[t]{3}{*}{ IFN- $\beta$} & F: CCTCCAACACCTCTTCAACACG & KF741874.1 \\
\hline & R:TGGCGTGTGCGGTCAAT & \\
\hline & P: AGCAGCCCACACACTCCAAAACACT & \\
\hline \multirow[t]{3}{*}{$\mid L-1 \beta$} & F: GCTCTACTAGTCGTGTGTGATGAG & NM_204524.1 \\
\hline & R:TGTCGATGTCCCGCATGA & \\
\hline & P: CCACACTGCAGCTGGAGGAAGCC & \\
\hline \multirow[t]{3}{*}{ IL-6 } & F: GTCGAGTCTCTGTGCTAC & NM_204628.1 \\
\hline & R: GTCTGGGATGACCACTTC & \\
\hline & P: ACGATCCGGCAGATGGTGA & \\
\hline \multirow[t]{3}{*}{ |L-8 } & F: GCCCTCCTCCTGGTTTCA & NM_205498.1 \\
\hline & R: CGCAGCTCATTCCCCATCT & \\
\hline & P:TGCTCTGTCGCAAGGTAGGACGCTG & \\
\hline \multirow[t]{3}{*}{ IL-10 } & F: CATGCTGCTGGGCCTGAA & NM_001004414.2 \\
\hline & R: CGTCTCCTTGATCTGCTTGATG & \\
\hline & P: CGACGATGCGGCGCTGTCA & \\
\hline \multirow[t]{3}{*}{ CATH-1 } & F: GCTGACCCTGTCCGCGTCA & NM_001001605.3 \\
\hline & R: GAGGTTGTATCCTGCAATCAC & \\
\hline & P: CCTGATGACCAGCGGC & \\
\hline \multirow[t]{2}{*}{ CATH-2 } & F: CAAGGAGAATGGGGTCATCAG & NM_001024830.2 \\
\hline & R: CGTGGCCCCATTTATTCATTCA & \\
\hline \multirow[t]{3}{*}{ CATH-3 } & F: CCATGGCTGACCCTGTCC & NM_001311177.1 \\
\hline & R:TGATGGCTTTGTAGAGGTTGATG & \\
\hline & P: CGCAGCCACCGTGTTG & \\
\hline \multirow[t]{3}{*}{ CATH-B1 } & F:TGTTCCATAGATCAGCAG & NM_001271172.1 \\
\hline & R: ATTCAACCACTCCCAGATG & \\
\hline & P:TCCACCAGTTGCGGAT & \\
\hline
\end{tabular}


conditions used in this study these two reference genes, and also the reference genes chicken ribosomal protein S17 and chicken RAS related protein RAB14, did not change compared to each other. Results are shown as 'fold change': expression compared to either unstimulated cells (Figure 1) or as relative expression compared to a specific subset of stimulated cells (Figures 6, 7 and 8) due to undetectable levels of cytokine gene expression in control non-stimulated cells, hampering calculation of relative expression levels compared to unstimulated controls.

\section{Griess assay}

HD11 cells were stimulated with ODN-2006 as described above. Supernatant was collected to measure NO production. Briefly, $30 \mu \mathrm{L}$ of sample were added to the well in a 96-well flat bottom plate. An equal volume of $1 \%$ sulfanilamide (Merck, Darmstadt, Germany) was added in each well, followed by $30 \mu \mathrm{L} 0.1 \% \mathrm{~N}$-(1-naphthyl) ethylenediamine dihydrochloride (VWR) at room temperature for $5 \mathrm{~min}$. The nitrite concentration was determined by measuring optical density at $550 \mathrm{~nm}$. Sodium nitrite (Merck, Darmstadt, Germany,) was used as a standard to accurately determine the nitrite concentration in the cell supernatant.

\section{Isothermal titration calorimetry}

Interaction between CATH-B1 and E. coli LPS O111:B4 or ODN-2006 was tested using isothermal titration calorimetry (ITC). All ITC experiments were performed on a Low Volume NANO ITC (TA instruments - Waters LLC, New Castle, USA). LPS was diluted in PBS to $0.5 \mathrm{mg} /$ $\mathrm{mL}$ in $\mathrm{PBS} / \mathrm{H}_{2} \mathrm{O}, 3: 1 \mathrm{v} / \mathrm{v}$ (75\% PBS), rigorously vortexed for $5 \mathrm{~min}$ and added to the cell chamber $(167 \mu \mathrm{L})$. ODN2006 was diluted to $25 \mathrm{nM}$ in $75 \%$ PBS. The syringe was filled with a $50 \mu \mathrm{L}$ solution of $200 \mu \mathrm{M}$ CATH-B1 in $75 \%$ PBS. Titrations were incremental with $2 \mu \mathrm{L}$ injections (for LPS) or $1 \mu \mathrm{L}$ injections (for ODN-2006) at $300 \mathrm{~s}$ intervals. Experiments were performed at $37{ }^{\circ} \mathrm{C}$ and data were analyzed with the Nano Analyze software (TA instruments - Waters LLC).

\section{ELISA}

RAW 264.7 cells were prepared in a 96-well plate as described above. RAW cells were stimulated with $E$. coli LPS $(100 \mathrm{ng} / \mathrm{mL})$ in the presence or absence of $5 \mu \mathrm{M}$ CATH-B1 or CATH-2 for $24 \mathrm{~h}$. Cell supernatants were collected to measure cytokine expression. The mouse IL-6 ELISA kit (R\&D Systems, Minneapolis, MN) was used to determine the IL- 6 concentration of samples. This assay was performed following the manufacturer's protocol.

\section{Statistical analysis}

Data are represented as mean \pm SEM of three independent experiments for each group $(\mathrm{n}=3)$ and were analyzed by a T-test for two groups or by one-way ANOVA with Tukey's multiple comparisons test for more than two groups. Bio-Rad CFX Manager 3.0 software was used for qPCR data analysis. All the graphs were made using GraphPad Prism ${ }^{\circledR}$ 8.0.

\section{Results}

APEC induced CATH-B1 gene expression in macrophages $\mathrm{CATH}-\mathrm{B} 1$ protein has so far only been detected in the bursa of Fabricius, but CATH-B1 mRNA is found in

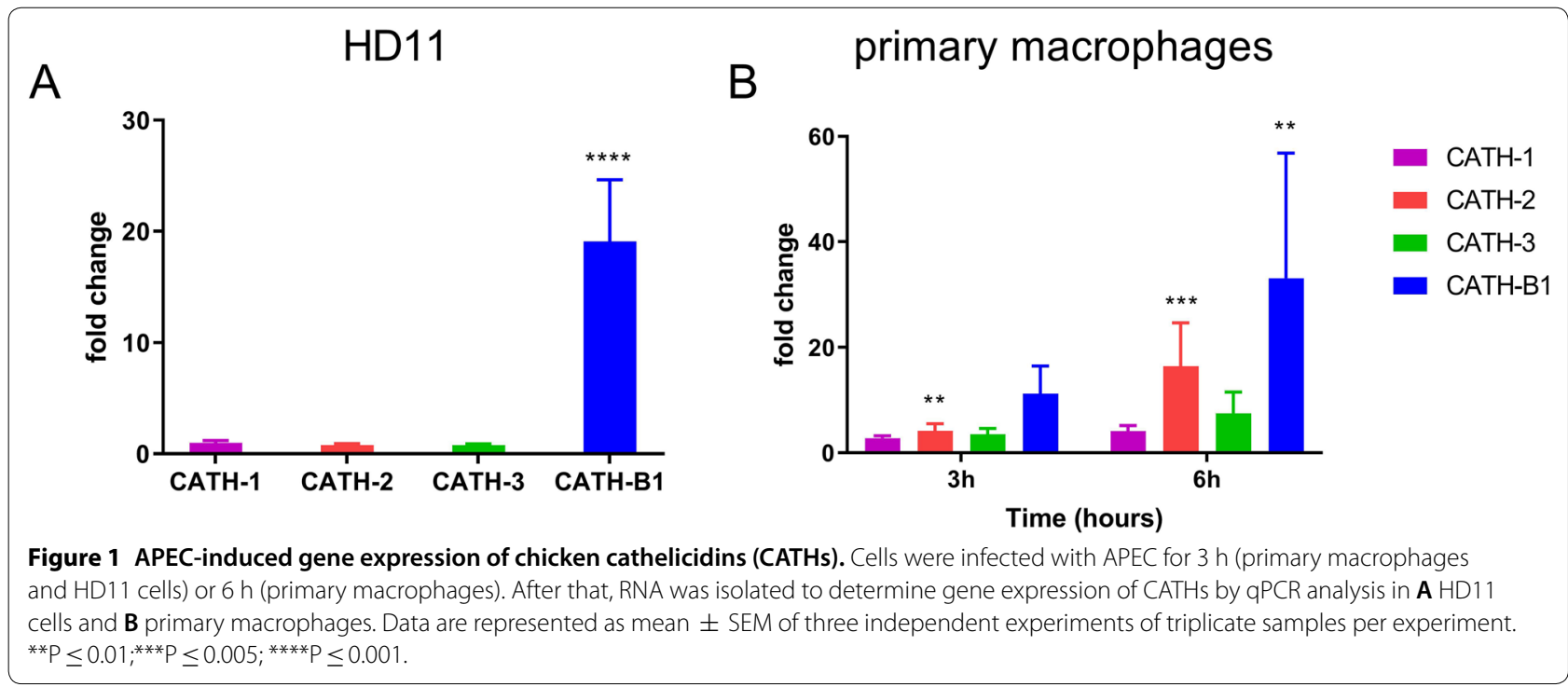


different tissues including the respiratory tract, gastrointestinal tract and lymphoid organs [23], indicating that a broader expression of CATH-B1 is likely. In our study, APEC significantly induced gene expression of CATHB1 in both HD11 cells (Figure 1A) and chicken primary macrophages (Figure 1B). At $6 \mathrm{~h}$ post-infection, up to a 30 -fold increase in CATH-B1 gene expression was detected in primary macrophages compared to noninfected cells (Figure 1B). Gene expression of CATH-1, $-2,-3$ was not or only mildly (CATH-2) induced by APEC in both cell types (Figures 1A, B).

\section{The effect of CATH-B1 on phagocytosis in macrophages}

To determine the effect of CATH-B1 on the function of macrophages, the peptide was added to primary macrophages or HD11 cells together with APEC. Bacterial phagocytosis by macrophages was concentration-dependent, significantly enhanced in HD11 cells (Figure 2A) when CATH-B1 was present, and slightly enhanced in primary macrophages (Figure $2 \mathrm{~B}$ ).

\section{Antibacterial activity of chicken cathelicidins against APEC} The antimicrobial activity against APEC in various culture media was tested for the four chicken cathelicidins (CATH-1, -2, -3 and -B1) in order to determine the minimal bactericidal concentration (MBC). This showed that CATH-1, -2, -3 had similar antibacterial activity with $\mathrm{MBC}$ values between $5 \mu \mathrm{M}$ and $10 \mu \mathrm{M}$. In contrast with the other three cathelicidins, CATH-B1 showed a weaker anti-APEC activity at $5 \mu \mathrm{M}$ but killed all bacteria at $10 \mu \mathrm{M}$ (Figure 3). In

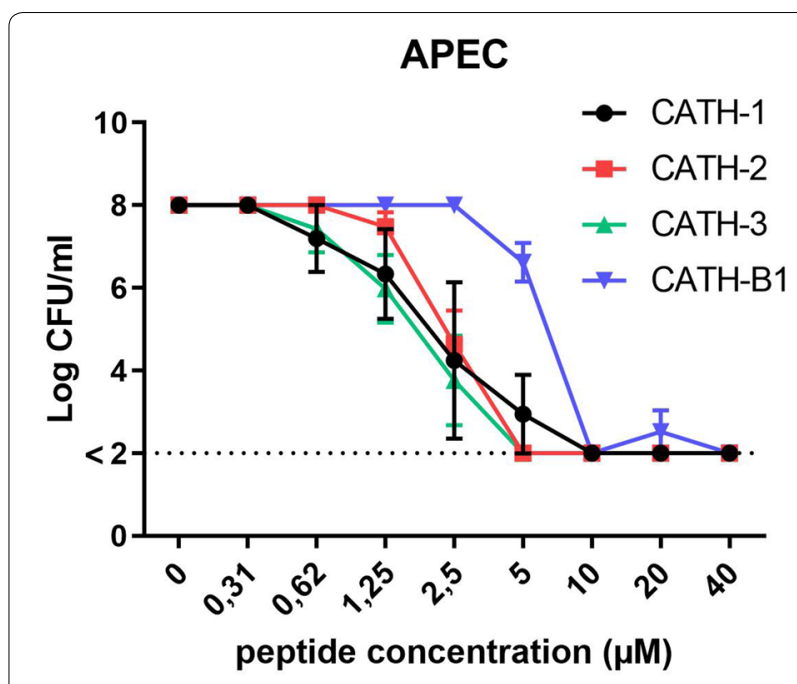

Figure 3 Antibacterial activity of chicken cathelicidins against APEC. Bacteria were incubated with different concentrations of cathelicidins for $3 \mathrm{~h}$, serially diluted and spread plated on TSA plates to quantify viable bacteria. Data are represented as mean \pm SEM of three independent experiments of triplicate samples per experiment.

cell culture conditions (DMEM + glutamax with $10 \%$ FCS), CATH-2 still showed strong antibacterial activity, whereas the antibacterial activity of $\mathrm{CATH}-1$ and CATH-3 was strongly reduced. CATH-B1 completely lost its antibacterial activity showing no growth inhibition of APEC at the highest concentration tested $(40 \mu \mathrm{M})$ (Additional file 1$)$.
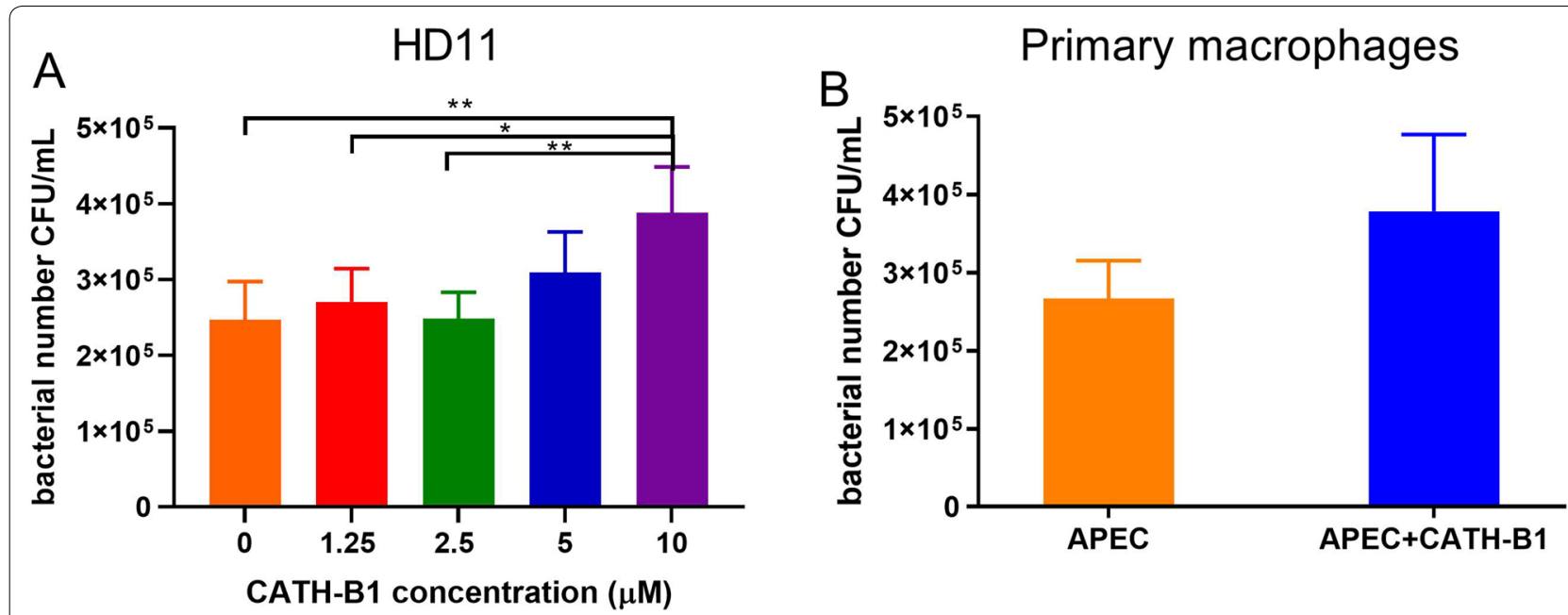

Figure 2 The effect of CATH-B1 on bacterial phagocytosis in chicken macrophages. Cells were infected with APEC for $3 \mathrm{~h}$ in the presence of 0-10 MM CATH-B1 (HD11 cells) or 5 MM CATH-B1 (primary macrophages), then gentamicin was added to kill extracellular bacteria for $1 \mathrm{~h}$. Finally, cells were lysed to quantify intracellular bacteria in $\mathbf{A}$ HD 11 cells and $\mathbf{B}$ in primary macrophages. Data are represented as mean \pm SEM of three independent experiments of triplicate samples per experiment. ${ }^{*} \mathrm{P} \leq 0.05 ;{ }^{* *} \mathrm{P} \leq 0.01$. 


\section{Cytotoxicity of CATH-B1}

To determine the toxic effect of CATH-B1 on host cells, the WST-1 assay was used to measure metabolic activity of primary macrophages. CATH-2 was used as a control in this study. It induced cell damage at $5 \mu \mathrm{M}$, at which a $40 \%$ reduction in metabolic activity was detected. CATHB1 was less toxic than $\mathrm{CATH}-2$ but reduced metabolic activity at concentrations of $10 \mu \mathrm{M}$ or higher (Figure 4). LPS and APEC actually increased metabolic activity when present, but did not have a significant effect on metabolic activity after co-incubation with cathelicidins.

\section{The effect of CATH-B1 on APEC-induced cytokine expression in macrophages}

Activation of macrophages resulting in the release of cytokines is a key immune response against pathogens. However, overexpression of inflammatory cytokines can cause apoptosis of cells leading to tissue damage. Therefore, it is important to have a balanced response of the immune system with respect to release of these cytokines. To investigate whether CATH-B1 regulates APEC-induced activation of macrophages, APECinduced cytokine expression in the presence or absence of CATH-B1 (and CATH-2 as control) was determined using qPCR. To separate immunomodulatory effects from antibacterial activity of CATH-B1, heat-killed APEC was also used in this experiment. At $3 \mathrm{~h}$ post infection, both viable and heat-killed APEC strongly up-regulated gene expression of pro-inflammatory cytokines IL- $1 \beta$ and IL-6, chemokine IL- 8 and the antiinflammatory cytokine IL-10 (Figure 5) compared to control cells that were mock-treated with medium. Both CATH-B1 and CATH-2 downregulated gene expression of these cytokines. Gene expression of IFN- $\beta$ was also upregulated by APEC and both CATH-B1 and CATH-2 significantly inhibited IFN- $\beta$ expression (Figure 5).
Interestingly, APEC-induced gene expression of IL-10 was increased by CATH-B1 and CATH-2 (Figure 5) but the increase was not significant.

To investigate how CATH-B1 inhibited APEC-induced activation, primary macrophages were pre-incubated with cathelicidins prior to or post APEC infection. APEC-induced gene expression after 3 and $6 \mathrm{~h}$ (depending on the setup of the experiment) was similar for IFN$\beta$, IL-1 $\beta$, IL-8 and IL-10, except for IL-6 gene expression, which was significantly higher after 6 h (Figure 6). The inhibitory effect of CATH-B1 on cytokine gene expression, observed in co-incubation conditions, was lost in pre- and post-incubation conditions. Noticeably, there was one exception, macrophages pre-incubated with CATH-B1 expressed significantly more IL-10 compared to macrophages without CATH-B1. Overall, this indicates an anti-inflammatory effect of CATH-B1 on APECinfected macrophages.

\section{The effect of CATH-B1 on LPS-induced cytokines expression in macrophages}

To further investigate the functional properties of CATHB1, E. coli LPS-induced cytokine gene expression in the presence or absence of cathelicidins was determined. Again, in these experiments CATH-2 was used as a positive control since CATH-2 has been described to neutralize LPS and that CATH-2- LPS binding was essential for this (Van Dijk et al. [30]). LPS-induced gene expression of IFN- $\beta$, IL-1 $\beta$, IL-6, IL-8 and IL-10 was significantly downregulated by both CATH-B1 and CATH-2 (Figure 7A). To investigate whether the inhibitory effect of CATH-B1 is host cell specific, we also tested IL-6 protein production in LPS-stimulated mouse macrophages using ELISA. Also, in mouse macrophages, the cytokine production was inhibited by CATH-B1 (Additional file 2), suggesting that the inhibition is due to the interaction
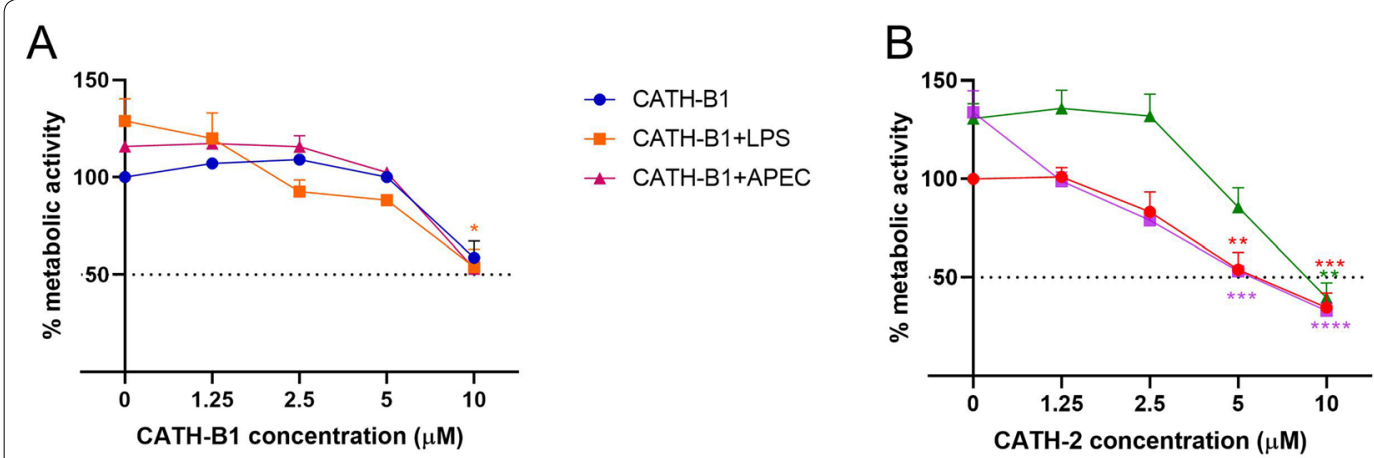

Figure 4 Cytotoxicity of chicken CATH-B1 and CATH-2. Primary macrophages were incubated with different concentrations $(0-10 \mu \mathrm{M})$ of CATH-B1 (A) and CATH-2 (B) for $3 \mathrm{~h}$ in the presence or absence of $100 \mathrm{ng} / \mathrm{mL}$ LPS or $1 \times 10^{6} \mathrm{CFU} / \mathrm{mL}$ APEC. Cathelicidins were washed away and cells were maintained in new medium for another $3 \mathrm{~h}$. Metabolic activity was tested using WST-1 reagent. Data are represented as mean \pm SEM of three independent experiments of triplicate samples per experiment. ${ }^{*} \mathrm{P} \leq 0.05 ;{ }^{* *} \mathrm{P} \leq 0.01 ;{ }^{* * *} \mathrm{P} \leq 0.005 ;{ }^{* * *} \mathrm{P} \leq 0.001$. 

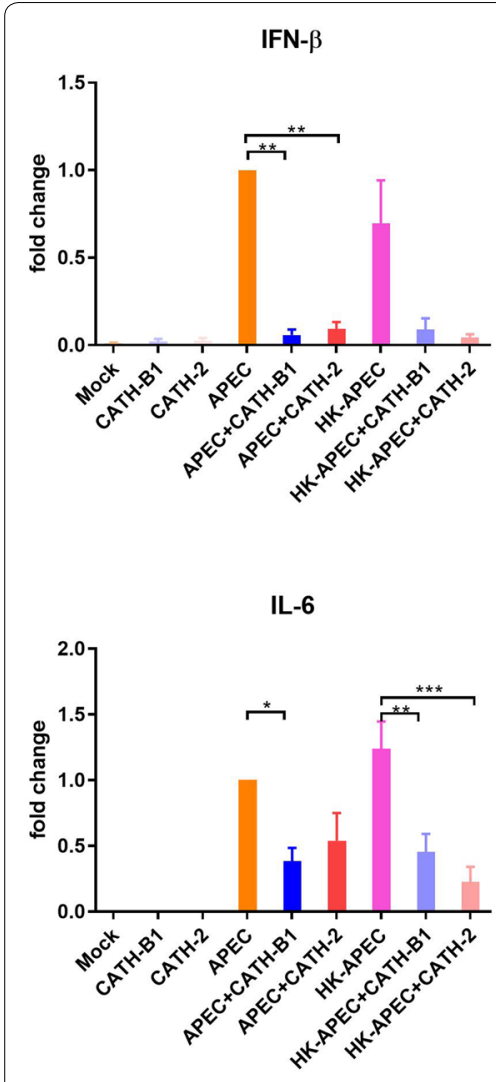

IL-1 $\beta$

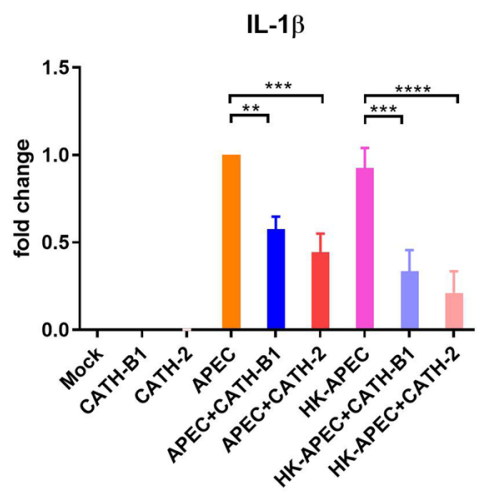

IL-10

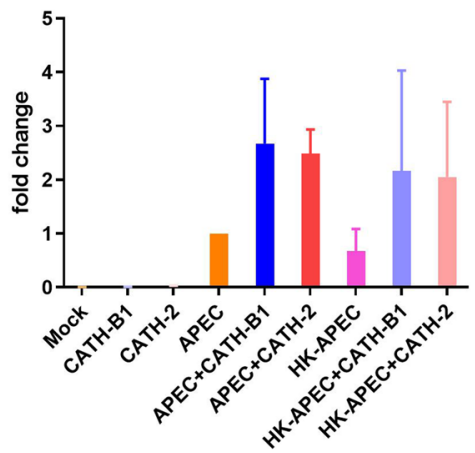

IL-8

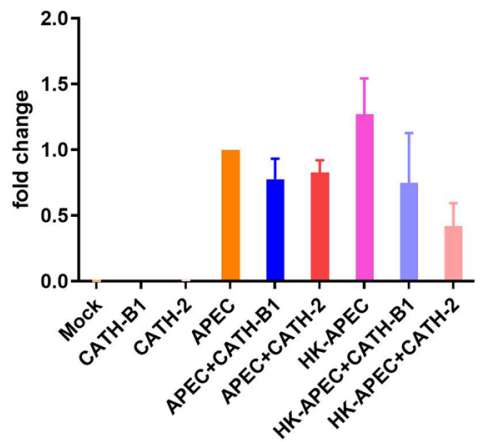

Figure 5 The effect of CATH-B1 on APEC-induced cytokine expression in primary macrophages. Gene expression of cytokines in primary macrophages was determined by qPCR at $3 \mathrm{~h}$ post infection in the presence or absence of $5 \mu \mathrm{M} \mathrm{CATH}-2$ and CATH-B1. Data are represented as mean \pm SEM of three independent experiments of triplicate samples per experiment. ${ }^{*} P \leq 0.05 ;{ }^{* *} P \leq 0.01 ;{ }^{* * *} \leq \leq 0.005 ;{ }^{* * * P} \leq 0.001$.

of CATH-B1 and LPS. Finally, ITC analysis was used to determine the direct interaction of CATH-B1 and LPS (Figure 7B). Peptide binding to LPS was detected with an observed dissociation constant of $\mathrm{Kd}=1.0 \mu \mathrm{M}$ in a reaction driven by both enthalpy $(\Delta \mathrm{H}=-19.6 \mathrm{~kJ} / \mathrm{mol})$ and entropy $\Delta \mathrm{S}=51.3 \mathrm{~J} / \mathrm{mol}$ ). This indicates that CATHB1 inhibits LPS-induced cytokine expression in macrophages by binding to and thereby neutralizing LPS, similar as has been described for CATH- 2 .

\section{The effect of CATH-B1 on DNA-induced NO production in HD11 cells}

Extracellular microbial DNA is an important signaling molecule in infection and inflammation. Bacterial DNA can be released from phagolysosomes after phagocytosis and bacterial degradation by macrophages, leading to activation of bystander macrophages [24]. CATH-2 has been shown to increase uptake of extracellular DNA and boost subsequent TLR9 or TLR21 activation [11]. To investigate whether CATH-B1 enhances DNAinduced macrophage activation, as shown before for CATH-2, HD11 cells were incubated with ODN-2006 in the presence or absence of CATH-B1 and CATH-2 as control. HD11 cells were used in these experiments since they are better NO producers than primary macrophages. ODN-2006-induced NO production was determined by the Griess assay. HD11 cells did not produce NO without stimulation nor did cathelicidins alone induce NO, whereas high concentration of ODN-2006 (40 $\mathrm{nM}$ ) strongly increased the NO production (data not shown). The ODN-2006-induced NO production was clearly enhanced by the presence of CATH-2 and CATH-B1, although a higher concentration of $5 \mu \mathrm{M}$ CATH-B1 was needed to reach maximal NO production compared to CATH-2 (Figure 8A). This shows that although the overall effect of CATH-B1 on stimulation of macrophages by APEC is inhibitory, the potential to increase stimulation by enhancing uptake of bacterial DNA is also present. For CATH-2, it was shown that the increased response of macrophages towards ODN2006 was depended on direct binding of CATH-2 to ODN-2006 [11]. Using ITC, it was shown that CATH-B1 indeed also strongly binds ODN-2006 (Figure 8B) with a $\mathrm{Kd}$-value of $64 \mathrm{nM}$. This binding between CATH-B1 and 

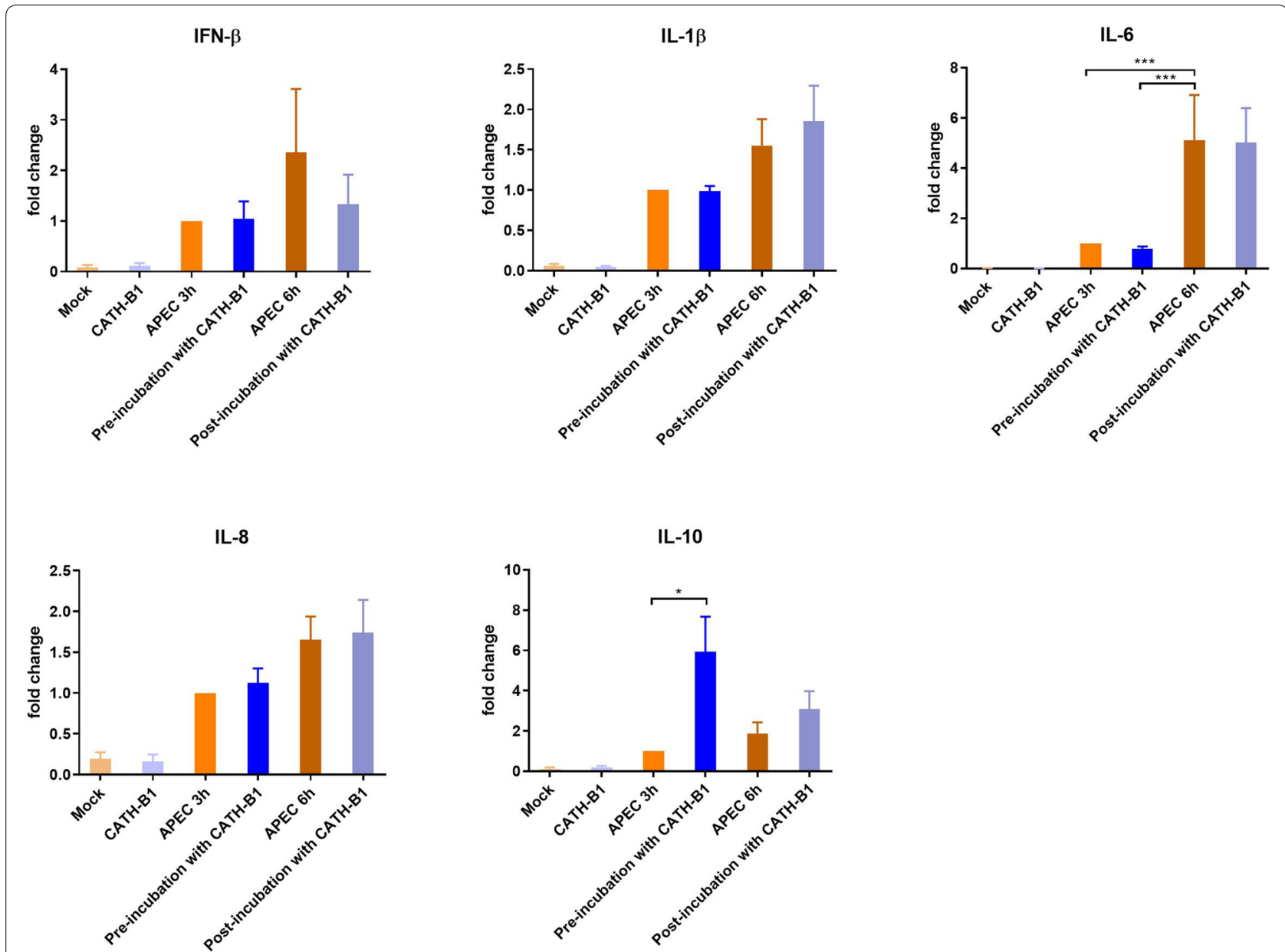

Figure 6 APEC-induced cytokine expression in primary macrophages upon pre- and post-incubation of CATH-B1. Primary macrophages were pre-incubated with $5 \mu \mathrm{M}$ CATH-B1 for $3 \mathrm{~h}$ before APEC infection, or post-incubated to $5 \mu \mathrm{M}$ CATH-B1 for $3 \mathrm{~h}$ after APEC infection. Then, gene expression of cytokines was determined by qPCR. Data are represented as mean \pm SEM of three independent experiments of triplicate samples per experiment. ${ }^{*} \mathrm{P} \leq 0.05 ;{ }^{* * *} \mathrm{P} \leq 0.005$

DNA was enthalpy-driven $(\Delta \mathrm{H}=-65.5 \mathrm{~kJ} / \mathrm{mol})$ with a negative entropy value $(\Delta \mathrm{S}=-73.5 \mathrm{~J} / \mathrm{mol})$.

\section{Discussion}

So far, four cathelicidins have been characterized in chicken, CATH-1, -2, -3, and -B1. In this study, we showed that APEC upregulates gene expression of CATH-B1 in macrophages but not of CATH-1, -2, -3. Recently, it was found by our group that CATH-B1 has strong antiviral activity against influenza A viruses in vitro [14]. In this study, the immunomodulatory effect of CATH-B1 on APEC-, LPS- or ODN-2006-activated chicken macrophages was explored.

The expression of cathelicidins is regulated by many factors including inflammatory and microbial stimuli. In our study, APEC infection enhanced gene expression of CATH-B1 but no or limited upregulation of the other three cathelicidins genes was detected in chicken macrophages. CATH-1, -2, -3 , in contrast to CATH$B 1$, are mainly expressed in heterophils, indicating that CATH-B1 gene expression is regulated separately from CATH-1, - 2, -3 and might play a non-redundant role in macrophages. Similarly, butyrate which has known immunostimulatory activity was previously shown to enhance gene expression of CATH-B1 (but not CATH$1,-2,-3)$ in chicken primary monocytes. Butyrate also enhanced antibacterial activity of primary monocytes against $S$. enteritidis [20]. In contrast to APEC infection, CATH-B1 gene expression was actually downregulated in peripheral blood leukocytes from a Salmonella typhimurium-infected chicken [25], but its expression was not affected by Campylobacter jejuni infection, suggesting that regulation of $\mathrm{CATH}-\mathrm{B} 1$ expression is dependent on the infecting bacterial species, and likely also on the cell type studied. However, since gene expression and protein 

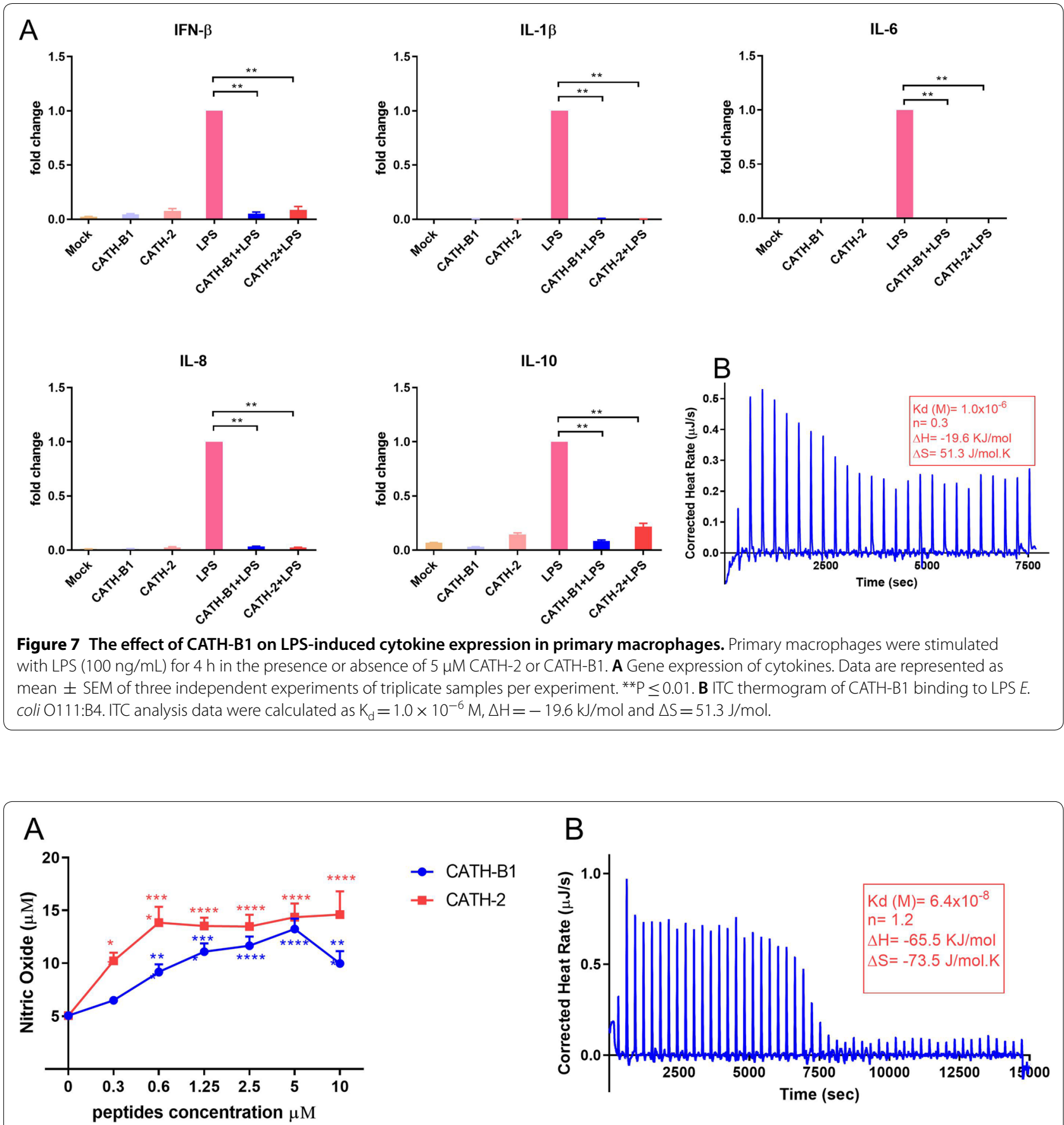

Figure 8 The effect of CATH-B1 on DNA-induced nitric oxide production in HD11 cells. HD11 cells were stimulated with 5 nM ODN-2006 for $20 \mathrm{~h}$ in the presence or absence of different concentrations of cathelicidins. A The amount of $\mathrm{NO}$ in the cell supernatant were measured by Griess assay. Data are represented as mean \pm SEM of three independent experiments of triplicate samples per experiment. ${ }^{* *} P \leq 0.01 ;{ }^{* * *} P \leq 0.005$; ***P $\leq 0.001$ compared to the no peptide $(0 \mu \mathrm{M})$ sample. B ITC thermogram of CATH-B1 binding ODN-2006. ITC analysis data were calculated as $\mathrm{Kd}=6.4 \times 10^{-8} \mathrm{M}, \Delta \mathrm{H}=-65.5 \mathrm{~kJ} / \mathrm{mol}$ and $\Delta \mathrm{S}=-73.5 \mathrm{~J} / \mathrm{mol}$.

production do not always correlate, it is still needed to determine the localization and amount of CATH-B1 in different tissues and cells in normal and stimulated conditions.
Antimicrobial activity is an important function of cathelicidins. CATH-1, -2, -3 showed good anti-APEC activity, which is consistent with the described broad antimicrobial activity of CATH-1, $-2,-3$ against a set of 
both Gram-positive and Gram-negative bacteria [26]. Compared to the other three cathelicidins, the antimicrobial activity of CATH-B1 is less studied. CATH-B1 has only been tested against a limited number of bacterial strains including E. coli, S. aureus, and P. aeruginosa with minimal inhibitory concentration (MIC) values in the range of $0.63-2.5 \mu \mathrm{M}$ when tested against a low number of bacteria $\left(2 \times 10^{3} \mathrm{CFU}\right)$ [6]. However, in another study the MIC value of CATH-B1 was as high as $12.8 \mu \mathrm{M}$ against $E$. coli and $S$. aureus using a higher number of bacteria [27], more closely resembling the results of this study. In addition, CATH-B1 had very weak anti-APEC activity in cell culture conditions, suggesting that direct killing of bacteria might not be the main activity of this cathelicidin.

Many studies have tried to correlate structure, charge and hydrophobicity to the antimicrobial activity of peptides. Chicken CATH-1, $-2,-3$ are largely unstructured in aqueous solution but can form an $\alpha$-helical amphipathic conformation in a membrane-mimicking environment $[5,28,29]$. Proline residues often induce a kink in the helical structure of cathelicidins and this kink between the two helices is involved in antibacterial activity [28, 30]. The structure of CATH-B1 has been predicted, but its conformation has not been determined. However, there are some clear differences between CATH-1, -2, -3 and CATH-B1. CATH-B1 is longer and contains a lower number of positively charged residues (Additional file 3). These differences could at least partially explain the observed difference in antimicrobial activity of CATHB1, but future structure-activity studies should be performed to determine which characteristics of CATH-B1 play a role in its antimicrobial activity.

In addition to direct microbial killing, cathelicidins can exert immunomodulatory effects on host cells. In previous studies, it has been shown that CATH-2 can strongly reduce activation of macrophages by neutralization of bacteria or bacterial products. In fact, it was hypothesized that CATH-2 has a dual role in first killing a pathogen and subsequently reducing an unwanted inflammatory reaction towards the dead bacterium (or its products) [12]. Our results showed that CATH-B1 inhibited both viable- and heat-killed APEC-induced inflammatory responses in macrophages, although CATH-B1 did not actually kill bacteria. Subsequent studies on LPS binding and neutralization of LPS-induced immune responses suggest that CATH-B1 exerted similar antiinflammatory properties to CATH-2, and several other host defense peptides [31, 32]. Unlike the immunomodulatory functions of the only human cathelicidin LL-37 that are described to be mediated by several receptors [33-35], it is still unknown whether chicken cathelicidins regulate immune response via interaction with specific cell receptors, or only act on bacterial ligands like LPS and DNA. Interestingly, when primary macrophages were preincubated with CATH-B1, upregulation of IL-10 expression was observed in response to APEC infection, suggesting that $\mathrm{CATH}-\mathrm{B} 1$ might modulate inflammation via interaction with host factors.

Besides anti-inflammatory activity, host defense peptides also exert pro-inflammatory effects on host cells [36]. In our previous study, CATH-2 has been shown to bind to DNA and enhance the DNA-induced TLR9/21 activation of macrophages [11]. Similar to CATH-2, our results in the current study showed that CATH-B1 also enhances DNA-induced NO production in macrophages, likely using a similar mechanism in which the cathelicidin binds to DNA and is taken up as a complex. ITC showed indeed that CATH-B1 strongly binds DNA, with similar entropy-driven binding characteristics as $\mathrm{CATH}$ 2 . This enhanced response was also induced by other host defense peptides, such as human/porcine cathelicidins and defensins [37-39]. The complexity of the combined cathelicidin pro- and anti-inflammatory activity makes it difficult to predict which activity will play a major role in a given situation in vivo, but it also indicates that it enables cathelicidins to maintain a balanced immune system in the host upon microbial challenge. In this respect an interesting feature of (some) cathelicidins is their ability of so-called silent killing of bacteria [12], in which bacteria are killed by cathelicidins but the unwanted subsequent immune activation by bacterial products is decreased at the same time. Unraveling the combination of anti-inflammatory and pro-inflammatory properties of cathelicidins will provide insight for development of therapeutic immunomodulators effective against microbial infection [40].

In this study, we found that CATH-B1 has no antibacterial activity in cell culture media. This corresponds with previous studies that many cathelicidins lose their antimicrobial activity in the presence of serum or physiological salt concentrations $[41,42]$. This means that in vivo other antimicrobial mechanisms are needed to kill bacteria. One such way could be that cathelicidins use their immunomodulatory properties to regulate the immune system. On the other hand, it has been shown that cathelicidins can have synergistic effects with other hostderived antimicrobial agents against invading pathogens, such as lysozyme and lactoferrin [43]. Therefore, participating in bacterial killing in in vivo conditions might still be an important feature of cathelicidins.

In conclusion, these studies show the overall antiinflammatory effect of CATH-B1 on APEC-infected or LPS-stimulated macrophages. This functional exploration of CATH-B1 provides a useful first set of information 
that justifies further investigations into the role of this less studied chicken cathelicidin in vivo.

\section{Supplementary information}

Supplementary information accompanies this paper at https://doi. org/10.1186/s13567-020-00849-y.

\section{Additional file 1. Antibacterial activity of chicken cathelicidins} against APEC in cell culture medium. Bacteria were incubated with different concentrations of cathelicidins in DMEM or RPMI1640 + glutamax containing FCS for $3 \mathrm{~h}$, serially diluted and spread plated on agar media to quantify viable bacteria. A Antibacterial activity of cathelicidins in DMEM + glutamax medium containing FCS. B Antibacterial activity of $5 \mu \mathrm{M}$ CATH-B1 in RPMI1640 + glutamax medium containing 10\% FCS. Data are represented as mean \pm SEM of three independent experiments of triplicate samples per experiment.

\section{Additional file 2. The effect of CATH-B1 on LPS-induced IL-6 protein} production in mouse macrophages. RAW cells were incubated with LPS $(100 \mathrm{ng} / \mathrm{mL})$ in the presence or absence of $5 \mu \mathrm{M}$ CATH-2 and CATH-B1. Concentrations of IL-6 in the cell supernatant were determined by ELISA. Data are represented as mean \pm SEM of three independent experiments of triplicate samples per experiment. ${ }^{*} \mathrm{P} \leq 0.05$.

Additional file 3. Characteristics of chicken cathelicidins.

\section{Abbreviations}

APEC: avian pathogenic Escherichia coli; CATH: cathelicidin; HDP: host defence peptide; IFN: interferon; IL: interleukin; ITC: isothermal titration calorimetry; LPS: lipopolysaccharide; MBC: minimal bactericidal concentration; NO: nitric oxide; PBMC: peripheral blood mononuclear cells; TLR: toll-like receptor; TSA: tryptic Soy Agar.

\section{Acknowledgements}

Not applicable.

\section{Authors' contributions}

LP performed all experiments and wrote the manuscript. EV and $\mathrm{HH}$ contributed to the design and supervision of the experiments and corrected the manuscript. RMvH and MRS contributed to the experiments and corrected the manuscript. All authors read and approved the final manuscript.

\section{Funding}

This work was supported by a personal fellowship from the China Scholarship Council (CSC) to Lianci Peng.

\section{Data availability statement}

All data sets generated for this study are included in the article.

\section{Ethics approval and consent to participate}

Not applicable.

\section{Consent to publish}

Not applicable.

\section{Competing interests}

The authors declare that they have no competing interests.

Received: 25 April 2020 Accepted: 13 September 2020

Published online: 24 September 2020

\section{References}

1. Kościuczuk EM, Lisowski P, Jarczak J, Strzałkowska N, Jóźwik A, Horbańczuk J, Krzyżewski J, Zwierzchowski L, Bagnicka E (2012) Cathelicidins: family of antimicrobial peptides. A review. Mol Biol Rep 39(12):10957-10970
2. Hemshekhar M, Anaparti V, Mookherjee N (2016) Functions of cationic host defense peptides in immunity. Pharmaceuticals 9(3):40

3. van Harten $R$, van Woudenbergh E, van Dijk A, Haagsman H (2018) Cathelicidins: immunomodulatory antimicrobials. Vaccines 6(3):63

4. Zanetti M (2005) The role of cathelicidins in the innate host defenses of mammals. Curr Issues Mol Biol 7(2):179-196

5. Xiao Y, Cai Y, Bommineni YR, Fernando SC, Prakash O, Gilliland SE, Zhang G (2006) Identification and functional characterization of three chicken cathelicidins with potent antimicrobial activity. J Biol Chem 281(5):2858-2867

6. Goitsuka R, Chen-lo HC, Benyon L, Asano Y, Kitamura D, Cooper MD (2007) Chicken cathelicidin-B1, an antimicrobial guardian at the mucosal M cell gateway. Proc Natl Acad Sci USA 104(38):15063-15068

7. Van Dijk A, Veldhuizen EJ, van Asten AJ, Haagsman HP (2005) CMAP27, a novel chicken cathelicidin-like antimicrobial protein. Vet Immunol Immunopathol 106(3-4):321-327

8. Van Dijk A, Molhoek E, Bikker F, Yu P-L, Veldhuizen E, Haagsman HP (2011) Avian cathelicidins: paradigms for the development of anti-infectives. Vet Microbiol 153(1-2):27-36

9. Van Dijk A, Tersteeg-Zijderveld MH, Tjeerdsma-van Bokhoven JL, Jansman AJ, Veldhuizen EJ, Haagsman HP (2009) Chicken heterophils are recruited to the site of Salmonella infection and release antibacterial mature Cathelicidin-2 upon stimulation with LPS. Mol Immunol 46(7):1517-1526

10. van Dijk A, van Eldik M, Veldhuizen EJ, Tjeerdsma-van Bokhoven HL, de Zoete MR, Bikker FJ, Haagsman HP (2016) Immunomodulatory and antiinflammatory activities of chicken cathelicidin-2 derived peptides. PLos One 11(2):e0147919

11. Coorens M, van Dijk A, Bikker F, Veldhuizen EJ, Haagsman HP (2015) Importance of endosomal cathelicidin degradation to enhance DNAinduced chicken macrophage activation. J Immunol 195(8):3970-3977

12. Coorens M, Schneider VA, de Groot AM, van Dijk A, Meijerink M, Wells JM, Scheenstra MR, Veldhuizen EJ, Haagsman HP (2017) Cathelicidins inhibit escherichia coli-induced t/r2 and t/r4 activation in a viability-dependent manner. J Immunol 199(4):1418-1428

13. Cuperus T, van Dijk A, Matthijs MG, Veldhuizen EJ, Haagsman HP (2016) Protective effect of in ovo treatment with the chicken cathelicidin analog D-CATH-2 against avian pathogenic E. coli. Sci Rep 6:26622

14. Peng L, Du W, Balhuizen MD, Haagsman HP, de Haan CAM, Veldhuizen EJA (2020) Antiviral activity of chicken cathelicidin B1 against influenza A virus. Front Microbiol 11:426

15. Sekelova Z, Stepanova H, Polansky O, Varmuzova K, Faldynova M, Fedr R, Rychlik I, Vlasatikova L (2017) Differential protein expression in chicken macrophages and heterophils in vivo following infection with Salmonella Enteritidis. Vet Res 48(1):35

16. Guabiraba R, Schouler C (2015) Avian colibacillosis: still many black holes. FEMS Microbiol Lett 362(15):fnv118

17. Toth T, Siegel P, Veit H (1987) Cellular defense of the avian respiratory system. Influx of phagocytes: elicitation versus activation. Avian Dis:861-867

18. Ariaans MP, Matthijs MG, van Haarlem D, van de Haar P, van Eck JH, Hensen EJ, Vervelde L (2008) The role of phagocytic cells in enhanced susceptibility of broilers to colibacillosis after infectious bronchitis virus infection. Vet Immunol Immunopathol 123(3-4):240-250

19. Matthijs MG, Ariaans MP, Dwars RM, van Eck JH, Bouma A, Stegeman A, Vervelde $L$ (2009) Course of infection and immune responses in the respiratory tract of IBV infected broilers after superinfection with $E$. coli. Vet Immunol Immunopathol 127(1):77-84

20. Sunkara LT, Achanta M, Schreiber NB, Bommineni YR, Dai G, Jiang W Lamont S, Lillehoj HS, Beker A, Teeter RG (2011) Butyrate enhances disease resistance of chickens by inducing antimicrobial host defense peptide gene expression. PLoS One 6(11):e27225

21. Peng $L$, van den Biggelaar RHGA, Jansen CA, Haagsman HP, Veldhuizen EJA. A method to differentiate chicken monocytes into macrophages with proinflammatory properties. Immunobiology. 2020:152004

22. van den Biggelaar $R$, Arkesteijn GJA, Rutten $V$, van Eden $W$, Jansen CA (2020) In vitro chicken bone marrow-derived dendritic cells comprise subsets at different states of maturation. Front Immunol 11:141

23. Achanta M, Sunkara LT, Dai G, Bommineni YR, Jiang W, Zhang G (2012) Tissue expression and developmental regulation of chicken cathelicidin antimicrobial peptides. J Anim Sci Biotechnol 3(1):15

24. Charrel-Dennis M, Latz E, Halmen KA, Trieu-Cuot P, Fitzgerald KA, Kasper DL, Golenbock DT (2008) TLR-independent type I interferon induction in 
response to an extracellular bacterial pathogen via intracellular recognition of its DNA. Cell Host Microbe 4(6):543-554

25. Meade KG, Narciandi F, Cahalane S, Reiman C, Allan B, O'Farrelly C (2009) Comparative in vivo infection models yield insights on early host immune response to Campylobacter in chickens. Immunogenetics 61(2):101-110

26. Veldhuizen EJ, Brouwer EC, Schneider VA, Fluit AC (2013) Chicken cathelicidins display antimicrobial activity against multiresistant bacteria without inducing strong resistance. PLoS One 8(4):e61964

27. Takeda A, Tsubaki T, Sagae N, Onda Y, Inada Y, Mochizuki T, Okumura K, Kikuyama S, Kobayashi T, Iwamuro S (2014) Bacterial toxin-inducible gene expression of cathelicidin-B1 in the chicken bursal lymphoma-derived cell line DT40: functional characterization of cathelicidin-B1. Peptides 59:94-102

28. Xiao Y, Herrera Al, Bommineni YR, Soulages JL, Prakash O, Zhang G (2009) The central kink region of fowlicidin-2, an a-helical host defense peptide, is critically involved in bacterial killing and endotoxin neutralization. J Innate Immun 1(3):268-280

29. Bommineni YR, Dai H, Gong YX, Soulages JL, Fernando SC, DeSilva U, Prakash O, Zhang G (2007) Fowlicidin-3 is an a-helical cationic host defense peptide with potent antibacterial and lipopolysaccharide-neutralizing activities. FEBS J 274(2):418-428

30. Van Dijk A, Molhoek EM, Veldhuizen EJ, Tjeerdsma-van Bokhoven JL, Wagendorp E, Bikker F, Haagsman HP (2009) Identification of chicken cathelicidin-2 core elements involved in antibacterial and immunomodulatory activities. Mol Immunol 46(13):2465-2473

31. Hu Z, Murakami T, Suzuki K, Tamura H, Kuwahara-Arai K, Iba T, Nagaoka I (2014) Antimicrobial cathelicidin peptide LL-37 inhibits the LPS/ATPinduced pyroptosis of macrophages by dual mechanism. PLoS One 9(1):e85765

32. Scheenstra MR, van den Belt M, Tjeerdsma-van Bokhoven JL, Schneider VA, Ordonez SR, van Dijk A, Veldhuizen EJ, Haagsman HP (2019) Cathelicidins PMAP-36, LL-37 and CATH-2 are similar peptides with different modes of action. Sci Rep 9(1):4780

33. Yang D, Chen Q, Schmidt AP, Anderson GM, Wang JM, Wooters J, Oppenheim JJ, Chertov O (2000) LL-37, the neutrophil granule-and epithelial cell-derived cathelicidin, utilizes formyl peptide receptor-like 1 (FPRL1) as a receptor to chemoattract human peripheral blood neutrophils, monocytes, and T cells. J Exp Med 192(7):1069-1074

34. Elssner A, Duncan M, Gavrilin M, Wewers MD (2004) A novel P2X7 receptor activator, the human cathelicidin-derived peptide LL37, induces IL-1 $\beta$ processing and release. J Immunol 172(8):4987-4994
35. Tokumaru S, Sayama K, Shirakata Y, Komatsuzawa H, Ouhara K, Hanakawa Y, Yahata Y, Dai X, Tohyama M, Nagai H (2005) Induction of keratinocyte migration via transactivation of the epidermal growth factor receptor by the antimicrobial peptide LL-37. J Immunol 175(7):4662-4668

36. Easton DM, Nijnik A, Mayer ML, Hancock RE (2009) Potential of immunomodulatory host defense peptides as novel anti-infectives. Trends Biotechnol 27(10):582-590

37. Lande R, Gregorio J, Facchinetti V, Chatterjee B, Wang Y-H, Homey B, Cao W, Wang Y-H, Su B, Nestle FO (2007) Plasmacytoid dendritic cells sense self-DNA coupled with antimicrobial peptide. Nature 449(7162):564

38. Baumann A, Démoulins T, Python S, Summerfield A (2014) Porcine cathelicidins efficiently complex and deliver nucleic acids to plasmacytoid dendritic cells and can thereby mediate bacteria-induced IFN- $a$ responses. J Immunol 193(1):364-371

39. Tewary P, de la Rosa G, Sharma N, Rodriguez LG, Tarasov SG, Howard OZ, Shirota H, Steinhagen F, Klinman DM, Yang D (2013) B-Defensin 2 and 3 promote the uptake of self or CpG DNA, enhance IFN-a production by human plasmacytoid dendritic cells, and promote inflammation. J Immunol 191(2):865-874

40. Mookherjee N, Anderson MA, Haagsman HP, Davidson DJ (2020) Antimicrobial host defence peptides: functions and clinical potential. Nat Rev Drug Discov 19(5):311

41. Johansson J, Gudmundsson GH, Rottenberg MNE, Berndt KD, Agerberth B (1998) Conformation-dependent antibacterial activity of the naturally occurring human peptide LL-37. J Biol Chem 273(6):3718-3724

42. Coorens M, Scheenstra MR, Veldhuizen EJ, Haagsman HP (2017) Interspecies cathelicidin comparison reveals divergence in antimicrobial activity, TLR modulation, chemokine induction and regulation of phagocytosis. Sci Rep 7(1):1-11

43. van der Linden DS, Short D, Dittmann A, Yu P-L (2009) Synergistic effects of ovine-derived cathelicidins and other antimicrobials against Escherichia coli O157: H7 and Staphylococcus aureus 1056 MRSA. Biotech Lett 31(8):1265-1267

\section{Publisher's Note}

Springer Nature remains neutral with regard to jurisdictional claims in published maps and institutional affiliations.
Ready to submit your research? Choose BMC and benefit from:

- fast, convenient online submission

- thorough peer review by experienced researchers in your field

- rapid publication on acceptance

- support for research data, including large and complex data types

- gold Open Access which fosters wider collaboration and increased citations

- maximum visibility for your research: over $100 \mathrm{M}$ website views per year

At BMC, research is always in progress.

Learn more biomedcentral.com/submissions 